\title{
Sepsis in frail patient
}

\author{
Andrea Beltrame, Emanuele Nadir Malfatto, Marco Anselmo \\ Infectious Diseases Unit, S. Paolo Hospital, ASL 2 Savona, Italy
}

\begin{abstract}
Frailty is defined as a clinical syndrome in which three or more of the following criteria are present: unintentional weight loss, self-reported exhaustion, weakness (grip strength), slow walking speed and low physical activity. Sepsis is defined as an inflammatory response to infection, with severe sepsis and septic shock being the most severe forms. The incidence of severe sepsis increases with older age and several studies have shown that there are many risk factors that predispose the elderly to a higher incidence of sepsis. Pre-existing co-morbidities such as cancer, diabetes, obesity, human immunodeficiency virus, and renal or pulmonary disease can cause sepsis, but other factors including poor lifestyle habits (i.e., smoking, drug or alcohol abuse), malnutrition, and endocrine deficiencies, which are frequent in the elderly, may also predispose to severe infections. Other risk factors for sepsis include recurrent hospitalization, especially in the Intensive Care Unit, and nursing home residence, where interventions such as urinary catheterization or multiple drug use are quite frequent and many studies reported that people above 65 years of age are three times more likely to be admitted to hospital than those aged 16-64 years, and have a higher risk of prolonged hospital stays, institutionalization and death. Clinical evaluation of the frail patient with sepsis poses some challenges. The immune response becomes progressively less efficient with increasing age thereby causing an altered response to infection and it is important to know that the clinical evaluation of the so-called fragile patient with severe infection should take into account the sometimes unusual signs and symptoms that, if identified, can lead to early diagnosis. Laboratory diagnostics can also be of great help in this setting. The treatment of sepsis in the fragile patient can be empirical or based on microbiological culture. Moreover, frail patient population presents many clinical problems with numerous comorbidities, therefore anti-infective treatment is difficult, so the physician's armamentarium must include many antibiotic drugs, of which there are far more available for the treatment of sepsis caused by Gram-positive bacteria than for sepsis caused by Gram-negative ones or fungi.
\end{abstract}

\section{Introduction}

Frailty has always been considered synonymous with disability, comorbidity and other characteristics, but it may have a biological basis and be a distinct clinical syndrome. ${ }^{1,2}$ In fact, it is associated with advanced age and chronic, but non-specific disease, and there is no standardized definition or valid screening method for those who are truly frail.

Numerous geriatric interventions have been de-

Correspondence: Andrea Beltrame, Infectious Diseases Unit, S. Paolo Hospital, via Genova 30, 17100 Savona, Italy. E-mail: a.beltrame@asl2.liguria.it

Key words: Frail patients; sepsis; antimicrobial treatment.

Received for publication: 6 October 2016.

Revision received: 26 October 2016.

Accepted for publication: 26 October 2016.

This work is licensed under a Creative Commons Attribution NonCommercial 4.0 License (CC BY-NC 4.0).

CCopyright A. Beltrame et al., 2016

Licensee PAGEPress, Italy

Italian Journal of Medicine 2016; 10:349-353

doi:10.4081/itjm.2016.799 veloped to improve clinical outcomes for frail older

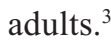

People above 65 years of age are three times more likely to be admitted to hospital than those aged 16-64 years, and have a higher risk of prolonged hospital stays, institutionalization and death. However, older age alone is not a sensitive predictor of inpatient mortality. 4,5

An important study based on data from the Cardiovascular Health Study involving 5317 men and women aged 65 years or older, defined a series of distinctive traits for frailty.

There is growing consensus that markers of frailty should include low physical activity and age-associated declines in lean body mass, strength, endurance, balance, and walking performance, and that several of these signs must be present to constitute frailty.

Frailty is defined as a clinical syndrome in which three or more of the following criteria are present: unintentional weight loss, self-reported exhaustion, weakness (grip strength), slow walking speed and low physical activity.

These authors believe that there is also an intermediate frailty status, as indicated by the presence of only one or two of the criteria. ${ }^{1}$

Therefore, advanced age alone is not a significant predictor of inpatient mortality, but some studies have shown that people over 65 years of age are three times 
more likely to be admitted to hospital than those aged 16-64 and that they occupy about two-thirds of acute hospital beds. ${ }^{4,5}$

Sepsis is defined as an inflammatory response to infection, with severe sepsis and septic shock being the most severe forms. ${ }^{6}$ The incidence of severe sepsis increases with older age and several studies have shown that there are many risk factors that predispose the elderly to a higher incidence of sepsis. ${ }^{7}$

Pre-existing co-morbidities such as cancer, diabetes, obesity, human immunodeficiency virus, and renal or pulmonary disease can cause sepsis, but other factors including poor lifestyle habits (i.e., smoking, drug or alcohol abuse), malnutrition, and endocrine deficiencies, which are frequent in the elderly, may also predispose to severe infections. ${ }^{8-11}$

Other risk factors for sepsis include recurrent hospitalization, especially in the Intensive Care Unit, and nursing home residence, where interventions such as urinary catheterization or multiple drug use are quite frequent. $^{7}$

Thus, the elderly are also at increased risk for colonization by Gram-negative multi-drug resistant organisms. ${ }^{12}$

Keeping the immune system of elderly and frail patients in mind is also quite important.

Their immune system is abnormal and there are functional impairments in both cell-mediated immunity and humoral immune responses. Memory cells have limited proliferative capacity in response to antigens, and B-cells and plasma cell populations also gradually decrease with aging. ${ }^{13}$

Moreover, frailty has also been associated with abnormalities in many physiological and biochemical systems. These include anemia, low albumin levels, elevated markers of inflammation, low levels of insulinlike growth factor-1 and dehydroepiandrosterone-sulfate, high hemoglobin A1c and micronutrient deficiencies. ${ }^{4,7}$

All these factors predispose to infections and sepsis.

\section{Clinical evaluation and diagnosis}

Clinical evaluation of the frail patient with sepsis poses some challenges.

We know that the immune response becomes progressively less efficient with increasing age thereby causing an altered response to infection. ${ }^{13}$

It is well known that older patients, particularly those with comorbidities, may be affected by severe infections without presenting any of the typical symptoms, such as fever, which may be absent in $30-50 \%$ of cases. ${ }^{14,15}$ This is mainly due to alterations in the thermoregulatory mechanisms: the presence of shivering and vasoconstriction may be observed, while hypothalamic regulation and thermogenesis are altered in old age. ${ }^{16}$
Among the less specific symptoms, we may observe weakness, malaise, delirium, confusion, loss of appetite, urinary incontinence or falls to the ground, any of which may be the only indicators of an underlying infection. ${ }^{17}$

Laboratory markers of inflammation may also be minimally altered, often leading to a delay in administering appropriate therapy. ${ }^{17}$

Generally speaking, elderly patients with severe infections, unlike younger subjects, are not able to accurately relay their symptoms, thus requiring us to resort to clinical tools in order to classify the patient.

Therefore, in the presence of a suspected infection, laboratory tests are of great importance.

Blood samples must be collected for blood cultures, urine samples for urine cultures and for the antigenic search for Streptococcus pneumoniae and Legionella pneumophila when we suspect, or find evidence of, pulmonary infection. ${ }^{17}$

In the presence of a possible invasive fungal infection, particularly Candida [e.g., in patients with some evidence of colonization and carriers of central venous catheters (CVC) undergoing total parenteral nutrition and/or recent major surgery], it may be useful to evaluate for the antigen $\beta$-d-glucan serum marker. ${ }^{17}$

Rectal swabs should be collected from patients in nursing-home residences or who have recently been hospitalized in order to rule out colonization by multi resistant enterobacteria. The results of the swab would be useful for establishing the most appropriate antibiotic therapy. ${ }^{18}$

In case of diarrhea, the search for Clostridium difficile toxin should always be performed in institutionalized patients. ${ }^{19}$ The collection of sputum for culture tests is of limited value, although sometimes it may be of help. ${ }^{17}$ Low albumin and high C-reactive protein values were found to be independent risk factors for mortality in the elderly.,

Radiological exams may be abnormal in frail patients with pneumonia or may be non-specific, given also the possible presence of pre-existing or underlying conditions such as heart failure. The appearance of wheezing alone may be a sign of sepsis, even in the absence of radiological evidence of pneumonia. ${ }^{20}$

It follows that the clinical evaluation of the socalled fragile patient with severe infection should take into account the sometimes-unusual signs and symptoms that, if identified, can lead to early diagnosis. Laboratory diagnostics can also be of great help in this setting.

\section{The treatment of sepsis in the fragile patient}

We usually consider the frail patient population to be made up of a very large number of patients. This population presents many clinical problems with nu- 
merous comorbidities, therefore anti-infective treatment is difficult. ${ }^{1,21,22}$

However, since the beginning of the $21^{\text {st }}$ century one of the main problems in case of bacteremia and sepsis is the increase in Gram-negative bacterial infections. Mortality ranges from 12 to $38 \%$ and depends on the timeliness and correctness of antibiotic therapy, as is the case for other etiologic agents. ${ }^{23}$ Bacteremia and septic shock by Gram-negative bacteria must be managed from the therapeutic point of view before achieving potential microbiological isolation. ${ }^{24,25}$

In recent years, issues related to Gram-negative infections have become critical in all larger hospitals. Moreover, an increasing percentage of Gram-negative organisms have become resistant to many antibiotics and treatment has become very difficult. ${ }^{25,26}$

The American National Healthcare Safety Network (NHSN) recently issued a report on resistance in Gramnegative infections (2009-2010) involving 27,766 patients with sepsis: i) Acinetobacter baumannii has a $67 \%$ resistance rate to carbapenems; ii) Klebsiella pneumoniae has a $13 \%$ resistance rate to carbapenems (although in 2015, in Italy it was actually between $25-40 \%$ ); iii) Escherichia coli has a $42 \%$ resistance rate to fluoroquinolones; iv) Pseudomonas aeruginosa has a $31 \%$ resistance rate to fluoroquinolones and a $26 \%$ resistance rate to cephalosporins and to $3^{\text {rd }}$ and $4^{\text {th }}$ generation carbapenems.

In the treatment of sepsis, we may consider an empirical preparatory treatment rather than targeted treatment in case of bacterial culture isolation. Taking into account only frail patients with severe sepsis or septic shock who have risk factors for Pseudomonas aeruginosa, or inpatients in hospitals where the resistance level as a percentage of Gram-negative bacteria is between $20-25 \%,{ }^{23}$ the proposed scheme includes aminoglycoside + one of the following: cefepime 2 g every 8 $\mathrm{h}$ or ceftazidime $2 \mathrm{~g}$ every $8 \mathrm{~h}$ or piperacillin - tazobactam $4.5 \mathrm{~g}$ every $6 \mathrm{~h}$ or meropenem $1 \mathrm{~g}$ every $8 \mathrm{~h}{ }^{23-26}$

A separate chapter is warranted for panresistant Gram-negative sepsis such as K. pneumoniae-producing carbapenemase (KPC). Nowadays, this is a problem in our hospitals, especially in frail, elderly patients who are hospitalized at length and undergo multiple courses of antibiotics, in particular carbapenem, or who are colonized by KPC. Approximately $20 \%$ of patients who are colonized by these bacteria suffer from severe sepsis, and mortality amounts to about $50 \% .^{27,28}$

Several reports claim the superiority of a combination therapy in these cases, and treatment usually consists of the following scheme: colistin $9,000,000$ $\mathrm{U}$ loading dose followed by 4.5 million $\mathrm{U}$ every $12 \mathrm{~h}$ intravenously (iv) + tigecycline $200 \mathrm{mg}$ loading dose followed by $100 \mathrm{mg}$ every $12 \mathrm{~h}$ or fosfomycin 4-6 g every 6-8 $\mathrm{h}$ or meropenem $2 \mathrm{~g}$ every $6 \mathrm{~h}$ if MICs are at least $\leq 32$ or aminoglycoside.
Antibiotic therapy should be reconsidered on the basis of new resistances that are developing: in some areas, $\mathrm{KPC}$ resistance to colistin may be as high as $30 \%$. The physician's armamentarium must include many antibiotic drugs, of which there are far more available for the treatment of sepsis caused by Grampositive bacteria than for sepsis caused by Gram-negative ones.

Furthermore, infections caused by CVCs or vascular devices are frequently related to problems such as osteomyelitis from soft tissue infection and endocarditis. $^{24,25,27-31}$

Treatment of severe sepsis by Gram-positive bacteria in the fragile patient should be evaluated based on the patient's additional risk factors and comorbidities and on the ecosystem of the hospital where they are being treated in relation to the percentage of methicillinresistant Staphylococcus aureus that is present.

A proposal for therapy might be: vancomycin 30 $\mathrm{mg} / \mathrm{kg}$ iv (usually $2 \mathrm{~g}$ continuous infusion) or teicoplanin $10-12 \mathrm{mg} / \mathrm{kg} /$ day iv administered once these molecules benefit from an initial loading dose. A good choice is also the association of a glycopeptide with a single daily dose of rifampicin $15 \mathrm{mg} / \mathrm{kg} /$ day iv.

But in some types of sepsis, such as the ones caused by CVCs, or in organ involvement (lung or soft tissue), several other options are available, such as: daptomycin $8-10 \mathrm{mg} / \mathrm{kg} /$ day iv administered in one single administration or linezolid $1.200 \mathrm{mg}$ iv in continuous infusion.

If microbiological findings reveal a methicillinsensitive $S$. aureus, then the choice could fall on: oxacillin $2 \mathrm{~g}$ iv every $6 \mathrm{~h} .{ }^{30-34}$

We have divided the therapeutic proposals for the treatment of sepsis regardless of whether etiology is Gram-positive or Gram-negative. Nonetheless, empirical approach therapy still remains valid when the causative agent is uncertain; in this case the recommendation is to associate: piperacillin-tazobactam $4.5 \mathrm{~g} \times 3$ iv (or continuous infusion) or meropenem $1 \mathrm{~g} \times 3$ iv + amikacin $15-20 \mathrm{mg} / \mathrm{kg} /$ day iv administered once + glycopeptide or daptomycin. ${ }^{27,28,35,36}$

In addition, it must be kept in mind that the frail patient is also susceptible to a certain frequency of sepsis caused by invasive fungal infections (IFI).

In recent Italian case studies, about $60 \%$ of patients with candidemia had been admitted to Internal Medicine Departments, thus confirming that sepsis targets the fragile patient. ${ }^{37}$ Even in this case, correct timing of the beginning of therapy is critical to outcome. Delaying the start of treatment beyond $96 \mathrm{~h}$ may result in a $40 \%$ to $50 \%$ mortality rate. Even among IFIs, we have observed a change in the relationship between Candida albicans/non albicans, thus, the recommendation for the empirical-rational therapy (which can also make use of the evaluation score rather than biochemical mark- 
ers) is the following: echinocandin, caspofungin starting dose of $70 \mathrm{mg} /$ day iv then $50 \mathrm{mg}$ iv/day or micafungin $100 \mathrm{mg}$ iv once/day or anidulafungin $2 \times 100 \mathrm{mg}$ iv starting dose then $100 \mathrm{mg}$ iv dosing.

If the antifungal sensitivity test indicates sensitivity to fluconazole, it may be subsequently administered at a dose of $800 \mathrm{mg}$ iv instead of echinocandin. ${ }^{38-42}$

Standardizing the timing of antibiotic therapy or antimycotic administration in the case of sepsis, especially in frail patients, is absolutely impossible. It is necessary to consider clinical and biochemical parameters and safety of therapy, and the therapeutic intervention should be tailored to the individual patient

\section{References}

1. Fried LP, Tangen CM, Walston J, et al. Frailty in older adults: evidence for a phenotype. J Gerontol 2001;56: M146-56.

2. Rockwood K, Stadnyk K, MacKnight C, et al. A brief clinical instruments to classify frailty in elderly people. Lancet 1999;353:205-6.

3. Winograd CH. Targeting strategies: an overview of criteria and outcomes. J Am Geriatr Soc 1991;39S: 25S-35S.

4. McMillan GJ, Hubbard RE. Frailty in older inpatients: what phisicians need to know. Q J Med 2012;105:1059-65.

5. Gordge L, De Young J, Wiechula R. Reducing functional decline of older people in an acute-care setting: are we providing adequate care to maintain/optimise the functional status of our elder patients?. Int J Evid Based Healthc 2009; 7:181-6.

6. Levy MM, FinkMP, Marshall JC et al. 2001 SCCM/ ESICM/ACCP/ATS/SIS International Sepsis Definitions Conference. Crit Care Med 2003;31:1250-6.

7. Nasa P, Juneja D, Singh O. Severe sepsis and septic shock in the elderly: An overview. World J Crit Care Med 2012;1:23-30.

8. Dombrovskiy VY, Martin AA, Sunderram J, et al. Rapid increase in hospitalization and mortality rates for severe sepsis in The United States: a trend analysis from 1993 to 2003. Crit Care Med 2007;35:1244-50.

9. Martin GS, Mannino DM, Moss M. The effect of age on the development and outcome of adult sepsis. Crit Care Med 2006;34:15-21.

10. Girard TD, Opal SM, Ely EW. Insights into severe sepsis in older patients: from epidemiology to evidence-based management. Clin Infect Dis 2003;40:719-27.

11. Walter LC, Brand RJ, Counsell SR, et al. Development and validation of a prognostic index for 1-year mortality in older adults after hospitalization. JAMA 2001;285: 2987-94.

12. Valenti WM, Trudell RG, Bentley DW. Factors predisposing to oropharyngeal colonization with gram-negative bacilli in the aged. N Engl J Med 1978;298:1108-11.

13. Opal SM, Girard TD, Ely EW. The immunopathogenesis of sepsis in elderly patients Clin Infect Dis 2005; 41:S504-12.

14. Henschke PJ. Infections in the elderly. Med J Aust 1993;158:830.
15. Musgrave T, Verghese A. Clinical features of pneumonia in the elderly. Semin Respir Infect 1990;5:269.

16. Bender BS, Scarpace PJ. Fever in the elderly. In: MacKowiak PA, ed. Fever: basic mechanisms and management. Philadelphia, PA: Lippincott-Raven; 1997. pp 363.

17. High K. Evaluation of infection in the older adult. UpToDate; 2016. Available from: http://www.uptodate.com/ contents/evaluation-of-infection-in-the-older-adult

18. Wang L, Lansing B, Symons K, et al. Infection rate and colonization with antibiotic-resistant organisms in skilled nursing facility residents with indwelling devices. Eur J Clin Microbial Infect Dis 2012;31:1797.

19. Fridkin S, Baggs J, Fagan R, et al. Vital signs: improving antibiotic use among hospitalized patients. MMWR Morb Mortal Wkly Rep 2014;63:194.

20. Musgrave T, Verghese A. Clinical features of pneumonia in the elderly. Semin Respir Infect 1990;5:269.

21. Suarez CJ, Lolans K, Villegas MV, et al. Mechanisms of resistence to beta-lactams in some common Gramnegative bacteria causing nosocomial infections. Expert Rev Anti Infect Ther 2005;3:915.

22. McCue JD. Gram-negative bacillary bacteriemia in the elderly: incidence, ecology, etiology and mortality. J Am Geriatr Soc 1987;35:213.

23. Kang C, Kim SH, Park WB. Bloodstream infection caused by antibiotic-resistant gram-negative bacilli: risk factor for mortality and impact of inappropriate initial antimicrobial therapy on out come. Antimicrob Agents Chemother 2005;4:760.

24. Albrecht SJ, Fishman NO, Kitchen J. Reemergence of gram-negative health care-associated bloodstream infections. Arch Intern Med 2006;166:1289.

25. Perez KK, Olsen RJ, Musick W. Integrating rapid diagnostics and antimicrobial stewardship improbe outcomes in patients with antibiotic-resistant Gram-negative bacteremia. J Infect 2014;69:216.

26. Richet H. Seasonality in Gram-negative and healthcareassociated infections. Clin Microbiol Infect 2012;18:934.

27. deKraker ME, Jarlier V, Monen JC. The changing epidemiology of bacteriaemias in Europe trend from the European Antimicrobial Resisstence Surveillance System. Clin Microbiol Infect 2013;9:860.

28. Orsi GB, Falcone M, Venditti M. Surveillance and management of multidrug-resistant microorganism. Exper tRev Anti Infect Ther 2011;9:653-79.

29. Qureshi ZA, Paterson DL, Peleg AY. Clinical characteristics of bacteriaemia caused by extended-spectrum beta-lactamase-producing Enterobacteriaceae in the era of CTX-M-type and KPC-type beta-lactamase. Clin Microbiol Infect 2012;18:887.

30. Polidori M, Nuccarini A, Tascini C. Vancomycin-resistantEnterococcus faecium (VRE) bacteriemia in infective endocarditis successfully treated with combination daptomycin and tigecycline. J Chemother 2011;66:1963-71.

31. Mermel LA, Allon M, Bouza E. Clinical practice guidelines for the diagnosis and management of intravascular catheter-related infection: 2009 Update by the Infectious Diseases Society of America. Clin Infect Dis 2009;49:1.

32. Falcone M, Serra P, Venditti M. Serious infections due to methicillin-resistant Staphylococcus aureus: an evolving challenge for physicians. Eur J Intern Med 2009;20:343-7. 
33. Steinkraus G, White R, Friedrich L. Vancomycin MIC creep in non-vancomycin-intermediate Staphylococcus aureus (VISA), vancomycin-susceptible clinical methicillin resistant S. aureus (MRSA) blood isolates from 201-2005. J Antimicrob Chemother 2007;60:140-5.

34. Kelesidis T, Humphries R, Ward K. Combination therapy with daptomycin, linezolid and rifampicin as treatmentoption for MRSA meningitis and bacteremia. Diagn Microb Infect Dis 2011;71:286-90.

35. Altun O, Almuhayawi M, Ullberg M, Ozenci V. Clinical evaluation of the FilmArray blood culture identification panel in identification of bacteria and yeasts from positive blood culture bottles. J Clin Microbiol 2013;51:4130.

36. Lau WK, Mercer D, Itani KM. Randomized, open label, comparative study of piperacillin-tazobactam administered by continuous infusion versus intermittent infusion for treatment of hospitalized patients with complicated intra-abdominal infection. Antimicrob Agents Chemother 2006;50:3556.

37. Bassetti M, Merelli M, Ansaldi F, et al. Clinical and ther- apeutic aspects of Candidemia: a five year single centre study. PLoS One 2015;10:e127534.

38. Arendrup MC. Epidemiology of invasive candidiasis. Curr Opin Crit Care 2010;16:445-52.

39. Tortorano AM, Kibbler C, Peman J. Candidaemia in Europe: epidemiology and resistance. Int J Antimicrob Agents 2006;27:359-66.

40. Concia E, Azzini AM, Conti M. Epidemiology, incidence and risk factors for invasive candidiasis in highrisk patients. Drugs 2009;69:5-14.

41. Posterano B, De Pascale G, Tumbarello M. Early diagnosis of candide mia in intensive care unit patients with sepsis a prospective comparison of (1-3)-beta-D-glucan assay, Candida score and colonisation index Crit Care 2011;15:R249.

42. Tortorano AM, Prigitano A, Dho G. ECMMM-FIMUA Study Group. Antifungal susceptibility profiles of Candida isolates from a prospective survey of invasive fungal infections in Italian intensive care unit. J Med Microbiol 2012;61:389-93. 